\title{
RETROCESO FORESTAL, DESAMORTIZACIONES Y ATRASO TECNOLÓGICO EN LA INDUSTRIA GUIPUZCOANA DEL HIERRO DURANTE EL ANTIGUO RÉGIMEN ${ }^{1}$
}

\author{
Álvaro Aragón Ruano \\ Universidad del País Vasco
}

\begin{abstract}
Resumen. El presente artículo tiene dos puntos de análisis básicos. Por un lado, hace un estudio diacrónico de la evolución del bosque guipuzcoano entre los siglos XVIII y XIX. El bosque fue una fuente de recursos muy disputada durante todo el Antiguo Régimen, y en torno a él se situaron una serie de intereses, cuya presión marcaría de una forma u otra el futuro del mismo, sobre todo a partir del mencionado período. Por otro lado, trata de averiguar las razones de lo que la historiografía ha definido como tradicional atraso tecnológico de las ferrerías durante los siglos XVI al XIX. A pesar de que, a partir del siglo XVI, Europa asistía a la expansión de los altos hornos, Guipúzcoa mantuvo sus ferrerías hidráulicas tradicionales sin apenas mejoras ni innovaciones tecnológicas. Por último, trata de demostrar que ambas cuestiones son imposibles de disociar y que están interrelacionadas. El monopolio y control que las autoridades locales y provinciales, muchas de las cuales tenían importantes intereses e inversiones en la industria de las ferrerías, ejercieron sobre los recursos forestales, permitió a las instalaciones siderúrgicas, sobre todo a partir de los procesos desamortizadores, contar con un combustible abundante, de calidad y barato, que dio la oportunidad de mantener los costes de producción a niveles rentables y hacer de la siderurgia tradicional guipuzcoana una actividad competitiva prácticamente hasta mediados del siglo XIX.
\end{abstract}

Palabras clave: Bosque, ferrerías, siglos XIV-XIX.

1 Trabajo recibido el 04/09/2007 y aceptado para su publicación el 27/12/2007.

La obtención de muchos de los datos que aquí se manejan ha sido posible a través de una estancia de investigación realizada en el año 2006 en la Universidad de Nevada (Reno), gracias a la concesión de una ayuda dentro del Programa USAC de la Universidad del País Vasco. 


\begin{abstract}
This article deals with two main subjects. On the one hand, its makes a diachronic study about the evolution of gipuzkoan woodland between the $18^{\text {th }}$ and the $19^{\text {th }}$ centuries. The forest was a disputed source of resources during the Ancien Regime, and some interests around it would define its future, over all since the period mentioned. On the other hand, the article tries to find the reasons of what historiography has defined as traditional technological backward of foundries from the $16^{\text {th }}$ to the $19^{\text {th }}$ centuries. Even if blast furnaces suffered a great development in Europe from the 16th onwards, Gipuzkoa kept its hydraulic forges without almost technological improvements. Finally, it tries to demonstrate that both are related to each other. The monopoly and control that local and regional authorities exerted over woodresources, most of which had important interests and investments in forges, allowed them to have a cheap and a high-quality fuel, which gave them the chance to keep the costs of production in profitable levels and to allow the gipuzkoan traditional iron industry became a competitive activity until almost the middle of the 19th century.
\end{abstract}

Keywords: Forest, forges, $14^{\text {th }}-19^{\text {th }}$ centuries.

\title{
1. El debate sobre la sostenibilidad de las actividades siderúrgicas
}

Las especies frondosas, como el roble, castaño, haya, etc. tienen un proceso largo de crecimiento lo que repercute negativamente en la sostenibilidad de su explotación. Un ejemplar de cualquiera de las especies mencionadas precisa del orden de 60 a 100 años para estar en sazón, es decir, para ser aprovechable, por ejemplo, para la construcción naval. Esta realidad hace que las mencionadas especies difícilmente puedan hacer frente a las demandas y necesidades industriales, que precisan de ingentes y continuas cantidades de madera. El equilibrio se mantiene cuando las exigencias industriales aún no son altas, pero en cuanto el ritmo depredador se acelera, las necesidades y la demanda de las actividades industriales superan y desbordan la oferta de madera que la naturaleza ofrece. Una alternativa bien pudiera ser la regeneración de la masa forestal o la reforestación de la superficie, pero nuevamente nos encontramos ante la realidad antes descrita, puesto que los bosques plantados artificialmente necesitan de un largo período de tiempo para ser aprovechables. Otra de las alternativas era la de crear un modelo de gestión que complementase la demanda de diferentes actividades y aumentase la productividad; los trasmochos guiados con "horca y pendón" o ipinabarros surgieron para complementar las necesidades de la ganadería, el carboneo y la construcción naval y permitieron aumentar la productividad, adelantando y aumentando el régimen de corte de las ramas. Pero este modelo también tenía sus limitaciones, entre las que estaba el ritmo de crecimiento o la pérdida del árbol como consecuencia de las malas prácticas en el corte ${ }^{2}$.

2 ARAGÓN RUANO, A.: El bosque guipuzcoano en la Edad Moderna: aprovechamiento, ordenamiento legal y conflictividad, Donostia, Sociedad de Ciencias Aranzadi, 2001, pp. 40-43. 
Uno de los grandes problemas a la hora de cuantificar el estado del arbolado en cada período es la escasez de datos. A diferencia de otros casos, como el vizcaíno ${ }^{3}$ o el gallego ${ }^{4}$, no existen catastros ni encuestas exhaustivas que nos permitan establecer series completas o aproximadas, lo que reduce a la mínima expresión la posibilidad de realizar estudios comparativos. Guipúzcoa cuenta únicamente con un estado -que es un mero recuento de árboles y presenta importantes deficiencias e inconvenientes- configurado en 1784, lo que obliga a aportar datos cuantitativos y cualitativos aislados, para poder dar una visión general y comparativa. A pesar de ello, podemos asegurar que la evolución del aprovechamiento del bosque guipuzcoano, y de la ecuación "actividad extractiva-actividad regeneradora" hizo que la situación del bosque guipuzcoano se transformase a lo largo del tiempo y del espacio, de forma que cuanto menor era el equilibrio entre ambos factores peor era el estado y la situación del arbolado: es decir, si a una actividad extractiva fuerte, pero equilibrada, no le acompañaba una fuerte actividad regeneradora, la deforestación no podía ser evitada; en caso de que la actividad extractiva fuese débil no era necesaria una fuerte y prolongada actividad regeneradora; sin embargo, ante una fuerte actividad extractiva, incontrolada y poco equilibrada, poco o nada podía hacer la más arriesgada y ambiciosa de las políticas regeneracionistas. Fue esta última tendencia la que acabó imponiéndose en el caso guipuzcoano, haciendo de la deforestación un problema irresoluble, a pesar de las medidas adoptadas, que obligó a finales del siglo XIX y comienzos del siglo XX a modificar el modelo forestal y a introducir especies foráneas de más rápido crecimiento.

Los recursos naturales imponen una realidad en la cual toda industria del hierro que deba tener en cuenta la escala presente y futura del abastecimiento de madera para la fabricación de carbón vegetal es una actividad con una producción limitada, en torno a cientos o, en el mejor de los casos, a miles de toneladas. Guipúzcoa estaría enmarcada en lo que Wrigley ha dado en llamar una economía orgánica, en la que el crecimiento vendría dado por la especialización de funciones, frente a un modelo en el que el crecimiento económico derivaría del éxito en el aprovechamiento de nuevas fuentes de energía calorífica y mecánica en el proceso productivo, y de la sustitución de las materias primas orgánicas por minerales. No obstante, uno de los grandes problemas que planteó durante mucho tiempo la alternativa a los combustibles vegetales, fue que el carbón mineral sólo representaba una fuente de calor en aquellas situaciones en las que no media-

3 Vizcaya cuenta con un "Estado general de los montes del Señorío, arbolados y demás" del año 1804. GOGEASKOETXEA, A.: Los montes comunales en la Merindad de Busturia, siglos XVIII-XIX, Bilbao, UPV, 1993, p. 19 y URIARTE AYO, R.: Estructura, desarrollo y crisis de la siderurgia tradicional vizcaina (1700-1840), Bilbao, UPV, 1988, pp. 85-90.

4 Galicia cuenta con el Catastro del Marqués de la Ensenada de 1752. REY CASTELAO, O.: Montes y política forestal en la Galicia del Antiguo Régimen, Santiago de Compostela, Universidad de Santiago de Compostela, 1995, p. 65. 
ba una interacción química entre la fuente de calor y el objeto calentado, como la que se producía en la fusión de metales. Las sustancias químicas del carbón eran transferidas al metal haciéndolo quebradizo o poseedor de alguna propiedad no deseada, por lo que hubieron de transcurrir casi dos siglos para que los combustibles inorgánicos, en este caso el carbón mineral, pasasen de tener un uso ordinario a generalizarse en la industria siderúrgica ${ }^{5}$. El hierro fundido, a través del método de alto horno, era quebradizo y duro, por lo que no podía moldearse utilizando las herramientas tradicionales de los herreros, aunque podía fundirse para fabricar ollas, hornos y cañones. La mayor parte de los productos, incluidas las piezas de maquinaria, clavos, cerrojos y herramientas debían hacerse en las fraguas, y para éstas era imprescindible el hierro forjado ${ }^{6}$.

Guipúzcoa se mantuvo prácticamente al margen de la aplicación de estas novedades, a pesar de conocerlas -puesto que por el puerto de Pasajes y San Sebastián, a partir de comienzos del siglo XIX, comenzaron a entrar importantes cantidades de carbón mineral inglés, aunque esencialmente para uso doméstico ${ }^{7}$-, prácticamente hasta finales del siglo XIX. Precisamente, el caso guipuzcoano careció durante el período que nos ocupa de las premisas apuntadas por Joel Mokyr como imprescindibles para fomentar la creatividad y la aplicación de innovaciones. En primer lugar, generalmente son las instituciones económicas y sociales las que deben estimular a los innovadores ofreciéndoles una adecuada estructura de incentivos, generalmente económicos, aunque también pueden ser de otra índole. En segundo lugar, la innovación requiere diversidad y, sobre todo, tolerancia, para poder vencer las fuerzas estabilizadoras que protegen el status quo -existentes en toda sociedad-, muchas de ellas procedentes de intereses muy arraigados que podrían sufrir pérdidas si se introdujeran novedades y muchas otras que se limitan simplemente a rechazar cualquier cambio; el conservadurismo en tecnología, la costumbre, la rutina o la adhesión al pasado producen una inercia económica contraria a las innovaciones. Parafraseando a Mokyr, estas fuerzas sociales representaban intereses distintos y se presentaban -y siguen presentándose actualmente- bajo una variedad de formas: defensores del medio ambiente, sindicatos, corporaciones gigantes, asociaciones profesionales, burocracias retrógradas o incompetentes. Además, cambiar un método de producción confiable y conocido es una verdadera apuesta, puesto que el peligro de fracaso, en sociedades que carecían de sistemas de seguridad, era mucho mayor que el actual ${ }^{8}$.

5 WRIGLEY, E.A.: Cambio, continuidad y azar. Carácter de la Revolución industrial inglesa, Barcelona, Crítica, 1992, pp. 97-98, 101.

6 MOKYR, J.: La palanca de la riqueza. Creatividad tecnológica y progreso económico, Madrid, Alianza Editorial, 1993, p. 122.

7 Archivo Municipal de San Sebastián, Fondo del Consulado, Libros 1, 9, 24, 25, 27, 45, 47 y 50.

8 MOKYR, J.: Op. cit., pp. 27-28, 195, 199 y 373. 
A pesar de que autores como Mokyr defienden que el cambio o la permanencia de algunas industrias tiene poco que ver con la demanda o con el suministro de materias primas y carbón, siendo las limitaciones tecnológicas y las oportunidades las que en conjunto determinaron dónde y cuándo se llevarían a cabo las mejoras, el caso guipuzcoano, como el norteamericano, viene a matizar tal extremo, puesto que sí existe una conexión directa entre la existencia de materias primas relativamente baratas y abundantes y la pervivencia de modelos productivos "arcaicos", al menos hasta que los modelos "innovadores" alcanzaron altas cotas de competitividad y eficiencia. En realidad, como explica el mencionado autor, coexisten dos teorías sobre la conexión entre los recursos naturales y el progreso tecnológico: una de ellas defiende que la abundancia de recursos naturales fomenta las innovaciones complementarias, mientras que la otra sostiene que la escasez de recursos naturales, como resultado de la aceleración o ralentización del crecimiento demográfico, estimula la búsqueda de sustitutos. Ninguna de las dos teorías sostiene que los recursos naturales o su ausencia sean una condición necesaria para que haya creatividad tecnológica, pero ambas sugieren que hay una estrecha correlación. Según el propio Joel Mokyr, ambas están mal planteadas, puesto que, aun admitiendo que existe una correlación entre ambas variables, la escasez de recursos y su demanda suponen un mecanismo de dirección, no una causa del progreso tecnológico. A pesar de que algunos historiadores económicos han intentado demostrar que algunas técnicas, en apariencia ineficaces, que sobrevivieron a pesar de la aparición de otras nuevas y mejores, eran en realidad elaboradas adaptaciones al entorno, no han conseguido convencer a los defensores del funcionalismo de que la prolongada supervivencia de una técnica implicase por fuerza eficacia. Lo cierto es que en la historia de la tecnología han convivido largos períodos de estancamiento, grandes cambios discontinuos y grandes mutaciones ${ }^{9}$.

De todas formas, las invenciones y su aplicación nunca fueron universales. En ello, por supuesto, tuvieron que ver causas endógenas y exógenas, factores sociales, económicos o culturales, que mostraron sus propias características en cada uno de los casos. Los sistemas que valieron para unos ámbitos no fueron aplicables para otros contemporáneamente, y hubieron de esperar al cambio de circunstancias y de marco económico para ponerse en marcha. Por tanto, las situaciones y la evolución en cada país fueron muy variadas. Las innovaciones aplicadas sobre la industria del hierro tuvieron principalmente dos campos: la propia actividad productiva y el método de obtención, y los combustibles.

Uno de los mayores logros de la metalurgia, cuyo primer desarrollo tuvo lugar en Alemania, Austria y Bohemia a partir del siglo XV, fue el de los altos hornos. Eran

9 Ibidem, pp. 112, 204-205, 352-353 y 361. 
éstos hornos de mayor tamaño que los de reducción, y gracias a fuelles hidráulicos, podían alcanzar altas temperaturas, lo que permitía que el hierro absorbiera un contenido superior de carbono, facilitando así la bajada del punto de derretimiento. Este hierro "crudo" podía ser vertido en lingoteras o convertido en hierro forjado, más maleable, por el método de la descarburación. El sistema del alto horno permitió producir hierro a menos costo, aunque la mayoría de las actividades siguieron precisando de la labor en hornos bajos hasta finales del siglo XIX. A partir del siglo XVI los altos hornos fueron evolucionando y mejorando en tamaño y eficiencia, de forma y manera que la producción de hierro fue en aumento con menos consumo de combustible. Uno de los avances más remarcables fue el de la fundición continua, que consistía en echar constantemente mineral y combustible en el horno, para obtener un flujo de hierro crudo. También en este período aparecieron los hornos de reverbero, en los que se eliminaba la chimenea y se utilizaban tubos subterráneos que permitían la entrada de aire fresco, lo que unido a un techo en forma de cúpula, revestido de arcilla refractaria, generaba temperaturas muy altas. Un tercer avance de importancia fue el de la trompa, hacia mediados del siglo XVI, que permitió, por medio de la utilización de la energía hidráulica, insuflar mayores cantidades de aire en la fragua. No obstante, todas estas innovaciones no consiguieron, de momento, evitar los costes de combustible y mano de obra, repercutiendo en el precio del hierro. En el campo de la refinería y el modelado del hierro, el avance más destacado fue la aparición del sistema rotatorio a finales del siglo XVI y comienzos del siglo XVII, primero en Lieja, y después en Inglaterra, que utilizaba energía hidráulica y constaba de talleres de laminado y talleres de cortado. Por último, en 1784 Henry Cort ideó el método de laminado y pudelado combinado, lo que aumentó enormemente la oferta de hierro forjado barato y de gran calidad.

El producto que más se resistió a los cambios fue el acero, producto intermedio, a medio camino entre el hierro forjado y el hierro crudo, obtenido por diferentes métodos. Además del método de crisoles, la descarburación o la cofusión, un cuarto método, que fue utilizado también en el ámbito guipuzcoano, fue el de carburación o cementación, consistente en la obtención de acero a partir del hierro forjado añadiéndole carbono. La producción de acero de alta calidad fue perfeccionada por Benjamín Huntsman, quien hacia 1740 ideó el acero de crisol, utilizando coque y hornos de reverbero para generar altas temperaturas, capaces de situar al acero en el punto de fusión. Sin embargo, el acero siguió siendo un producto excesivamente caro, que apenas tuvo presencia en la revolución industrial, en la que el hierro forjado fue el principal protagonista, hasta $1860^{10}$.

10 Ibidem, pp. 71, 87, 123, 125 y 126. 
El siglo XVIII fue testigo de otra de las grandes invenciones en la metalurgia, esta vez relacionado con el combustible y no con el proceso productivo, gracias al uso de coque en los altos hornos. Entre 1709 y 1750, años inmediatos a los descubrimientos de Darby para fundir el hierro por medio del coque, sólo se erigieron seis hornos al coque en toda Inglaterra, pues el carbón vegetal seguía garantizando mayor rentabilidad. Entre 1760 y 1790 la mayoría de los hornos ingleses fueron abandonando el carbón vegetal y se alimentaron de coque. Pero su aplicación en el continente se demoró: el primero en la Alta Silesia (Prusia) se abrió en 1796, en Francia en 1813 y en el Ruhr en 1849. Todavía en 1910 en Allentown (Estados Unidos de América) se construyeron dos altos hornos al carbón vegetal ${ }^{11}$.

Aunque el último alto horno a carbón vegetal dejó de trabajar en Inglaterra en 1810, siendo sustituido por el consumo de carbón mineral o coque, ningún alto horno con carbón mineral había sido todavía fabricado en USA, donde hasta la década de 1870 , cuando contaba con unos cuarenta millones de habitantes y con un proceso de industrialización que avanzaba con rapidez, la mitad de su demanda total de energía se cubría con madera ${ }^{12}$. El caso norteamericano cuenta con ciertas similitudes al caso guipuzcoano y merece la pena que nos detengamos unos instantes en él. El primer experimento con coque en USA fue hecho en 1835 y el último alto horno de carbón vegetal cerró en 1945. La causa de esta supervivencia es sin duda la cantidad de madera, pero también las calidades del hierro hecho con carbón vegetal: es resistente, fuerte, mantiene un buen filo cortador, es maleable, haciéndolo versátil para todos los usos en la frontera, para instrumentos, calderas, etc. Los altos hornos o blast furnace se localizaban en función de la disponibilidad de mineral, pues la madera era abundante en zonas determinadas de los Estados Unidos de América.

Durante el siglo XVIII muchos altos hornos norteamericanos, que esquilmaron los recursos con los que contaban, se trasladaron sin prejuicio alguno allí donde había madera. Desde 1840 los ferrones norteamericanos se dieron cuenta de que debían reducir los costos si querían ser competitivos en el mercado frente a los que utilizaban combustible mineral. De todas formas, algunos tenían abundante madera con lo que no estaban interesados en la reforestación. Para reducir los costos de combustible, los ferrones adoptaron progresivamente nuevas técnicas que les permitían utilizar más eficazmente sus bosques. Los propietarios de Shelby Works en Alabama insistieron a sus leñadores que cortasen cerca del suelo con serruchos en vez de con hachas, pues así podían salvar hasta el $20 \%$ de la madera para carbón. Para acrecentar el rendi-

11 LEGORBURU FAUS, E.: La labranza del hierro en el País Vasco: hornos ruedas y otros ingenios, Bilbao, Universidad del País Vasco, 2000, pp. 158-159 y MOKYR, J.: Op. cit., pp. 123-124.

12 WRIGLEY, E.: Op. cit., p. 150. 
miento, dejaron de fabricar su carbón vegetal en hoyos. De todas formas, no siempre la eficacia en los recursos resultaba suficiente para garantizar un aporte continuo y a precios competitivos. Muchos ferrones dependían de los mercaderes y abastecedores de madera para encontrar madera a bajo coste. La mayoría de los propietarios, sin embargo, debían elegir entre adquirir o gestionar los bosques para sostener la producción y consumir los bosques más cercanos e importar carbón de leña. Cada vez tenían que cortar más lejos la madera lo cual aumentaba los costos. Los ferrones de Michigan, sin embargo, descubrieron que podían traer el carbón vegetal en tren con un costo aceptable y podían comprar a grandes distancias, lo cual les salía más barato que añadir la gestión del bosque a sus costos.

En 1856 había en los Estados Unidos 560 altos hornos de hierro, de los cuales 439 , el 78\%, todavía consumía carbón vegetal. Este sistema perduró hasta los años 40 del siglo XX en Michigan y Wisconsin. Alrededor de cada horno había bosques de 12.150 a 40.500 hectáreas, que eran cortadas de forma rotacional. La extensión afectada podía ir de las 10.125 hectáreas en 1862 a las 38.070 hectáreas en 1890, cuando los cortes se hacían cada 25 o 30 años ${ }^{13}$. Todavía en 1880 los clientes seguían comprando productos fabricados con carbón de leña porque eran familiares o conocidos, productos de alta calidad con reputación contrastada en un tiempo en el que los usuarios todavía no tenían plena confianza en el acero de pudelado. El acero mejoró a partir de 1880. A medida que esto sucedía, los ferrones que utilizaban carbón vegetal asociados en la Charcoal Iron Workers' Association encontraron, en un mercado compartido, dificultades para sus caros productos, lo cual incidió más que la posible presión y dificultades de abastecimiento de combustible. A medida que iban perdiendo su cuota de mercado fueron perdiendo el romanticismo y la visión de gestión sostenible del bosque para uso industrial.

El momento álgido de la producción siderúrgica norteamericana se produjo entre 1720 y 1860 y el eclipse entre 1860 y 1900, fecha a partir de la cual se impuso la producción y el uso del acero. En definitiva, desde 1830 los estadounidenses, con sus abundantes bosques, no vieron mucha necesidad de usar innovaciones, como el fundido con coque, que utilizaban los ingleses para evitar pagar el alto precio del combustible maderero en Inglaterra. Sin embargo, en 1860 reconocen que las nuevas técnicas europeas de fabricación de acero, como el puddling o el proceso mecánico, más conocido como método Bessemer, eran inmediatamente utilizables en la economía americana ${ }^{14}$.

13 GORDON, R. B.: American Iron, 1607-1900, London, The John Hopkins University Press, 1996, pp. 40-44 y WILLIAMS, M.: Deforesting the earth: From Prehistory to Global Crisis, ChicagoLondon, The University of Chicago Press, 2002, p. 316.

14 GORDON, R. B.: Op. cit., p. 220. 


\section{La paradoja "retroceso forestal-disponibilidad de combustible"}

Entre 1650 y 1749, en Europa desaparecieron entre 18,4 y 24,6 millones de hectáreas de bosque, la mayoría por la acción destructiva de la agricultura, pues sólo un 12 ó 14\% de ellas fue por la acción de la siderurgia ${ }^{15}$. A pesar de no contar con datos numéricos, las informaciones de carácter cualitativo indican que fue también desde mediados del siglo XVII cuando, como consecuencia del proceso de ruralización que se produjo en la economía guipuzcoana, que dio lugar a la extensión de los pastos y áreas de cultivos a costa de la masa forestal, el estado del bosque empezó a volverse irreversible. Por supuesto, la variedad de situaciones era importante, puesto que en algunos municipios la salud de la masa forestal era buena, mientras que en otros ya era preocupante. Así en Azcoitia la situación era extrema, ya que en 1674 eran necesarios 400.000 plantíos, a fin de repoblar su jurisdicción, lo que provocó una petición desesperada al rey para obtener licencia de venta de tierras propias del concejo, para costear los plantíos ${ }^{16}$. La situación, de todas formas, parece que siguió empeorando, puesto que en 1765 la extensión despoblada llegaba a los 500.000 árboles $^{17}$, esto es, 1.370 hectáreas o el $13 \%$ de la extensión total del municipio ${ }^{18}$.

La situación hizo reaccionar a la Provincia, quien, en busca de soluciones, redactó el Reglamento de montes de 1738, que exigía un mayor esfuerzo repoblador, esencialmente para atender a la demanda de la siderurgia, ante su nuevo impulso, y protegerla de las ansias de la Corona. Consecuencia de dicha preocupación, que se extendía a toda la Corona de los Borbones, fue la redacción de las Ordenanzas de montes de 1748 y la particular para Guipúzcoa de 1749. El estado de algunos bosques particulares, no tan abundantes como los concejiles, sin embargo, no parece que fuese tan desesperado, a tenor de los datos que nos muestran que el Marqués de Valmediano poseía, en 1750, 1.502.365 árboles, 1.500.000 de ellos hayas, superando al propio concejo de Ataun ${ }^{19}$; estado satisfactorio que se explica por el predominio de hayas, menos codiciadas que el roble, y a que las principales posesiones del Marqués en Ataun quedaban geográficamente lejos de los principales puertos guipuzcoanos y cuencas siderúrgicas, por lo que su explotación fue más tardía, precisamente a partir de 1750.

15 WILLIAMS, M.: Op. cit., p. 191.

16 Archivo Municipal de Azcoitia (A.M.Azc.), 10-1/2.11.1.

17 Era tal la desolación de los bosques de la jurisdicción de Azcoitia, que José Baltasar de Palacios, síndico procurador de Azcoitia, acertaba a decir que ni en dos siglos, siguiendo el ritmo de repoblación aplicado, se llenaría el espacio vacío. A.M.Azc., 10-1/2.11.1.

18 Debe tenerse en cuenta que cuando la documentación hace referencia a superficie despoblada no habla de terrenos dedicados a la agricultura o la ganadería, sino a espacios baldíos, susceptibles de ser repoblados. Por tanto, la extensión del área despoblada de árboles eran mucho mayor.

19 A.G.G.-G.A.O., PT 1908, fols. 169 r ${ }^{\circ}-176 v^{\circ}$. 
Aunque los esfuerzos por recuperar la masa boscosa concejil fueron importantes, de forma que todas las villas superaban su obligación en los plantíos, la extensión de los baldíos desocupados era realmente alarmante. Aún más, el propio esfuerzo repoblador, que muestra que el estado de los bosques no era el idóneo, era relativo, pues, como denunciaba el Comisario de Marina, muchas villas lo cumplían “...por el objeto de cubrir la obligacion , y ganar quartillos... ", y una vez plantados los abandonaban ${ }^{20}$; era práctica común el trasplante de árboles demasiado delgados y separados, que por su estado debían seguir en los viveros, con el propósito de cumplir la obligación, lo que provocaba finalmente la pérdida del arbolito $^{21}$. El Comisario de Marina acusaba a las villas guipuzcoanas -a excepción de Tolosa ${ }^{22}$ - de practicar talas excesivas, tanto en árboles sazonados como en jóvenes, perjudicando los intereses de la Marina. Concretamente, el Comisario criticaba la poda de los trasmochos, realizada sin método, quedando inutilizados para todos los usos, y aconsejaba: “...para desterrar este vicio que tiene origen en los carboneros que solo aspiran a la pronta abundancia de leña sin hauerse de que quedan inutilizados los arboles; se impone a esta villa la precisa indispensable obligacion de que las primeras y segundas podas que se hicieren en arboles nuebos sea con asistencia y dirección de vn facultativo en la construccion por cuio medio se conseguira el que los arboles queden vtiles, y den mas leña en las subzesibas podas... "23. Por tanto, la masa boscosa se había reducido y presentaba un estado deplorable en algunos puntos de la provincia, a pesar de los esfuerzos, teniendo en cuenta además que éstos se iniciaron con ahínco desde 1750, lo que, dado el período vegetativo de las frondosas -en torno a los 50-60 años como mínimo-, obligaba a obtener resultados hacia la primera década del siglo XIX, como así sucedió.

El retroceso del bosque hasta 1749 había sido muy importante, pero los esfuerzos iniciados desde 1750 comenzaron aparentemente a obtener ciertos frutos en 1784. No obstante, el retroceso había sido tan fuerte que, a pesar de todo, el terreno deforestado era muy amplio como se infiere de la lectura de la tabla 1 y de los casi 900.000 árboles que se podían plantar en baldíos en 1765-1768. En 1784, Legazpia,

20 Expediente relativo a la segunda visita de montes en Astigarraga (15 de agosto de 1768). A.G.G.-G.A.O., JD IM 2/17/59.

21 Expediente relativo a la segunda visita de montes en Rentería (5 de agosto de 1768) y Expediente relativo a la segunda visita de montes en Zumárraga (5 de octubre de 1768). Ibidem.

22 En la segunda visita de los montes de Tolosa (17 de octubre de 1765) el Comisario Echeverria felicitó a la villa de Tolosa por su aplicación de las reglas: “...se infiere su esmero y aplicación a su fomento y conservación, no reconociendose en ellos con tanto exceso los desordenes y abusos que en otros de varias Republicas, pues el methodo moderno, con que estan echos los trasmochos, aunque no con la perfeccion que devieran, no son tan inutiles como todos cuantos se ha executado en otras jurisdiciones...". Archivo Municipal de Tolosa, C, 5, II, 2/1.

23 Expediente relativo a la segunda visita de montes en Segura (15 de noviembre de 1766). A.G.G.-G.A.O. JD IM 2/17/56. 
Retroceso forestal, desamortizaciones y atraso tecnológico en la industria guipuzcoana del hierro durante el Antiguo Régimen

Tabla 1: Árboles que se pueden plantar en baldíos (1765-1768)

\begin{tabular}{|c|c|c|c|c|c|}
\hline Lugar & Obligación 1750 & Obligación 1765-68 & Plantíos & Baldíos 1750 & Baldíos 1765-68 \\
\hline Anzuola & & & & & 28.000 \\
\hline Asteasu & 410 & & & & 100.000 \\
\hline Astigarraga & & & & & 29.000 \\
\hline Azpeitia & & 17.038 & 108.577 & & \\
\hline Beasain & & & & & 57.500 \\
\hline Cegama & & & & & 73.000 \\
\hline Eibar & & & & & 20.000 \\
\hline Elgueta & & & & & 16.000 \\
\hline Hernani & $1.750,5$ & & & & \\
\hline Irún & 421 & & & & \\
\hline Mondragón & & & & & 56.000 \\
\hline Ordicia & 458 & & & & 45.500 \\
\hline Oyarzun & & & & & 92.000 \\
\hline Placencia & & & & & 3.000 \\
\hline Segura & & & & & 122.000 \\
\hline Tolosa & 1.732 & & & 114.200 & \\
\hline Urrechu & 215 & & & & 30.000 \\
\hline Valle Real de Léniz & & & & & 154.700 \\
\hline Vergara & & & & & 40.000 \\
\hline Zumárraga & & & & & 15.000 \\
\hline TOTAL & & & & & 881.700 \\
\hline
\end{tabular}

Fuente: A.G.S., Secretaría de Marina, Leg. 578; A.G.G.-G.A.O., JD IM 2/17/56, 57 y 59; A.M.A., C, 5, 6/1; A.M.Or., Plantación de árboles, 1; A.M.I., C, 5, I, 8; A.M.H., C, 5, II, 4; A.M.U., C, 5, II, $2 / 1$ y A.M.T., C, 5, II, $2 / 1$.

que en 30 años había plantado 300.000 árboles, todavía tenía el triple de espacio baldío ${ }^{24}$; problemas que en esa villa se incrementaron a finales de siglo ${ }^{25}$. Si se analizan los datos aportados por las informaciones de $1784^{26}$ se aprecia que, a pesar de la apa-

24 A.M.L., 227-14.

25 Curiosamente, a través del análisis de los protocolos notariales correspondientes a Legazpia, se ha podido constatar como, desde 1780, no hubo ventas de montes, lo que, unido a la gran cantidad de escrituras para el remate de setos de viveros que se contratan, demuestra la brutal deforestación experimentada por los bosques en Legazpia, que obligaron al concejo a iniciar un plan de recuperación del mismo, para lo que fue necesaria la enajenación de abundantes terrenos baldíos, muchos de ellos adquiridos por el Marqués de San Millán. Amojonamiento de 2.918 posturas de terreno baldío concejil en Zatuierreca ( 24 de septiembre de 1789, Legazpia) a favor de Francisco de Guerra. A.H.P.G., 1/2290, fols. 207 ro -212 r $^{\circ}$.

26 Teniendo en cuenta que la superficie de Guipúzcoa sería de 199.700 hectáreas (188.878 sin tener en cuenta Oñate), la superficie ocupada por los 11 millones de árboles supondría el 15-16\% de la superficie de Guipúzcoa, esto es, una sexta parte del territorio. Sin embargo, según estimaciones de Ascasibar, los 11 millones de árboles censados ocuparían una extensión comprendida entre 25.000 y 30.000 hectáreas, que supondrían la cuarta parte de la superficie de la provincia. ASCASIBAR, J.: Los montes de Guipúzcoa, San Sebastián, 1978, p. 11. Por su parte, Arantxa Otaegui opina que la superficie forestal de Guipúzcoa abarcaría una extensión superior, puesto que faltan los datos de algunos municipios ricos en arbolado, como Aya, el recuento de localidades que pertenecen a la Unión de Enirio-Aralar, como son Abalcisqueta y Amézqueta, no está claro, no figura el número de árboles que cada municipio tenía reservado para la construcción y reparación de edificios, ni el número de plantíos que había en los viveros, y, por último, los ayuntamientos declararon un número de árboles inferior al real, considerando, que este inventario daría lugar a nuevas apropiaciones de madera para la Marina Real. OTAEGUI ARIZMENDI, A.: "El paisaje forestal de Gipuzkoa en 1784", en Actas del IX Congreso de Historia Agraria (Bilbao, 1999), San Sebastián, SEHA/ Departamento de Historia e Instituciones económicas de la UPV, 1999, pp. 481-486. 
rente riqueza forestal conseguida -entre un 20 y $25 \%$ de la superficie de la provincia-, la gran mayoría de árboles eran jóvenes, sin sazonar, por tanto, sin aprovechamiento, de momento. Como se puede apreciar en la tabla 2, la situación, en la mayoría de los casos, mejoró comparativamente, con respecto a 1749-1750 -a pesar de los pocos ejemplos con los que se cuenta- sobre todo, en casos significativos como los de Aizarnazábal, Alquiza, Elgóibar, Legazpia o Cizúrquil.

Tabla 2: Árboles en 1749-1750 y 1784

\begin{tabular}{|l|c|c|c|c|}
\hline Lugar & Concejil 1749 & Particular 1749 & Total 1749 & Total 1784 \\
\hline Aizarnazábal & 12.156 & 29.064 & 41.220 & 129.891 \\
\hline Alquiza & & & 10.000 & 112.687 \\
\hline Asteasu & & & 72.549 & 73.249 \\
\hline Ataun & 64.460 & 1.506 .762 & 1.571 .222 & 1.065 .403 \\
\hline Cizúrquil & 2.960 & 730 & 3.690 & 94.942 \\
\hline Elgóibar & 26.582 & 9.163 & 35.745 & 109.409 \\
\hline Legazpia & 26.085 & 3.464 & 29.549 & 64.405 \\
\hline Placencia & 19.635 & 12.190 & 31.825 & 28.300 \\
\hline Rentaría & 195.861 & 22.635 & 218.496 & 219.735 \\
\hline Zarauz & 54.000 & 30.820 & 84.820 & 47.675 \\
\hline
\end{tabular}

Fuente: A.G.G.-G.A.O., PT 1908, fols. 169 ro 176 vo; A.G.G.-G.A.O., PT 1765, fols. 168 r $^{\circ}$ y v ; A.G.G.-G.A.O., PT 1800, fols. $292 \mathrm{r}^{\mathrm{o}} \mathrm{y} \mathrm{v}^{\mathrm{o}}$; A.H.P.G., 1/2253, fols. $121 \mathrm{r}^{\mathrm{o}}-126 \mathrm{r}^{\mathrm{o}}$; A.H.P.G., 2/3184, fols. $276 \mathrm{r}^{\mathrm{o}}-277 \mathrm{v}^{\mathrm{o}}$; Ibidem, fols. $351 \mathrm{r}^{\mathrm{o}}-$ $352 \mathrm{v}^{\mathrm{o}}$; A.H.P.G., 1/3873, fols. $98 \mathrm{r}^{\circ}-104 \mathrm{r}^{\mathrm{o}}$; A.H.P.G., 3/2486, fols. $87 \mathrm{r}^{\mathrm{o}}-90 \mathrm{r}^{\mathrm{o}}$ y A.H.P.G., 1/1721, fols. $54 \mathrm{r}^{\mathrm{o}}-61 \mathrm{v}^{\mathrm{o}}$.

Tabla 3: Estado del arbolado en 1784

\begin{tabular}{|l|c|c|c|c|}
\hline Especies & Jóvenes & Sazonados & Viejos & Total \\
\hline Robles & 3.185 .176 & 1.078 .752 & 1.146 .525 & 5.430 .453 \\
\hline Hayas & 2.524 .236 & 1.475 .147 & 812.735 & 4.812 .118 \\
\hline Castaños & 374.263 & 212.254 & 292.399 & 878.916 \\
\hline Fresnos & 33.019 & 14.478 & 16.059 & 63.556 \\
\hline Nogales & 16.038 & 4.166 & 2.720 & 22.924 \\
\hline Total & 6.132 .732 & 2.804 .797 & 2.270 .438 & 11.237 .967 \\
\hline
\end{tabular}

Fuente: ASCASIBAR, J.: Op. cit., p. 9.

Precisamente, cuando los primeros resultados de la política regeneracionista debían empezar a recogerse en los montes concejiles, el proceso desamortizador, que ya se estaba produciendo desde el último tercio del siglo XVIII27, vino a dilapidar la recuperación de la foresta guipuzcoana. La reducción de los montes concejiles es indiscutible ya para 1818, como consecuencia de la enajenación de los bienes comunales. Es significativo el caso de Elgóibar, donde la extensión de los terrenos

27 OTAEGUI ARIZMENDI, A.: Guerra y crisis de la hacienda local: las ventas de los bienes comunales y de propios en Gipuzkoa 1764-1814, San Sebastián, Diputación Foral de Guipúzcoa, 1991, p. 19. 
baldíos superaba a la de los terrenos poblados ${ }^{28}$. En 1805 había en Hernani espacio para plantar 218.900 árboles $^{29}$. En 1818 Legazpia tenía la 1/6 parte de lo que tenía en $1738^{30}$. Tampoco los montes particulares permanecían ajenos a los problemas de deforestación. A pesar de que en los montes de Idia y Andaza, propiedad de la Real Colegiata de Roncesvalles, existían en la fecha 270.000 árboles, 70.000 bravos, 160.000 trasmochos y 40.000 plantíos, por valor de 97.500 duros, es decir, 1.950 .000 reales de vellón ${ }^{31}$, el Conde de Villafuertes, en 1817, alertaba sobre la mala situación de sus propios bosques y los de aquellos que tenían bienes vinculados ${ }^{32}$. Parece ser éste un fenómeno común en toda Europa, puesto que también en Francia, Inglaterra -donde el gran impacto de la construcción naval en el bosque se produjo desde $1780^{33}$-, Dinamarca, Suecia y Alemania se redujo de manera importante el bosque de robles en los siglos XVIII y XIX ${ }^{34}$. Michael Williams habla de que durante la Edad Moderna la masa forestal cayó 1/5: la masa forestal de Inglaterra y Gales cubría sólo un 7,7\% de su superficie, la de Irlanda un $12 \%$ en 1600, la del norte de Francia el 16,3\%, y la de Prusia un $40 \%$ hasta el siglo XVIII ${ }^{35}$.

Tabla 4: Posturas de montes concejiles (1738-1818)

\begin{tabular}{|l|c|c|c|}
\hline Lugar & $\mathbf{1 7 3 8}$ & Enajenadas (1738-1819) & $\mathbf{1 8 1 8}$ \\
\hline Alquiza & 75.875 & 68.288 & 7.587 \\
\hline Berástegui & 366.791 & 121.591 & 245.200 \\
\hline Elgóibar & 570.494 & $471.518,5$ & $98.975,5$ \\
\hline Ichasondo & 90.000 & 88.500 & 1.500 \\
\hline Tolosa & 280.934 & 75.520 & 205.414 \\
\hline Salinas de Léniz & 114.500 & 22.380 & 92.120 \\
\hline
\end{tabular}

Fuente: A.G.G.-G.A.O., JD IM 2/17/159.

Paradójicamente, el retroceso de la masa forestal y el aumento de la presión sobre los recursos forestales -derivados de la expansión demográfica, que conllevó la reactivación de las actividades siderúrgica y naval, el aumento del consumo doméstico, de la construcción de edificios, etc.-, provocó un reajuste en el sector siderúrgico.

28 De las $98.975,5$ posturas de montes que tenía Elgóibar en 1818, 36.773 posturas eran de jarales, 2.372 posturas de castaños y 59.830,5 de baldíos . A.G.G.-G.A.O., JD IM 2/17/159.

29 A.M.H., C, 5, I, 5/3.

30 A.M.L., 209-5.

31 Archivo de la Real Colegiata de Roncesvalles, Guipúzcoa, Caja 45, Fajo 02, 80.

32 Archivo de los Zavala, 104/14.

33 SIMMONS, I.G.: An Environmental History of Great Britain, from 10.000 years ago to the present, Edinburgh, University Press, 2001, p. 95.

34 ELIASSON, P. - NILSSON, S.G.: “"You should hate young oaaks and young noblemen” The Environmental History of oaks in Eighteen and Nineteenth Century Sweden", Environmental History, vol. $7, \mathrm{n}^{\circ} 4$, p. 672.

35 WILLIAMS, M.: Op. cit., p. 169. 
La progresiva subida del precio de la leña a partir de la década de los años treinta del siglo XVIII, cuyos máximos se registraron entre 1790 y 1808, acabó haciendo inviable la rentabilidad de un número importante de las ferrerías guipuzcoanas a fines del setecientos. Muchas de ellas, las más débiles, hubieron de cerrar sus puertas -definitivamente o momentáneamente, en espera de mejores tiempos-, mientras que las más competitivas -más fuertes estructural y financieramente- pervivieron, haciéndose además con toda la cuota de mercado dejada por el resto. Curiosamente, al reducirse el número de ferrerías, la extensión de bosque existente, aunque en franco retroceso, aumentó la disponibilidad de leña para carbón por unidad de explotación. Se debe tener en cuenta que para estas fechas, sobre todo, tras el desastre de Trafalgar, la demanda de madera por parte de la Corona para la construcción de buques reales prácticamente desapareció en el caso guipuzcoano, aunque la de la marina mercante se mantuvo, si bien durante el siglo XIX se produjo la consolidación del proceso iniciado en el siglo XVIII, en el que la construcción de grandes buques fue perdiendo progresivamente protagonismo y peso específico en las manufacturas navales vascas a favor de la construcción de pequeños y medianos vasos (más de la mitad inferiores a 50 toneladas) ${ }^{36}$, lo que dejó en manos de la industria siderúrgica la riqueza forestal guipuzcoana. Además, con las sucesivas desamortizaciones que se producirán durante el siglo XIX, gran parte de las propiedades concejiles serán desvinculadas y pasarán a manos de propietarios particulares, muchos de ellos dueños de ferrerías o interesados en la industria del hierro, dejando a su disposición grandes cantidades de leña.

La industria siderúrgica tradicional guipuzcoana, por tanto, se mantendrá activa casi hasta fines del siglo XIX, gracias precisamente a la disponibilidad de materia prima barata, y a pesar de su supuesto atraso tecnológico. Elena Legorburu advierte lagunas sin esclarecer, como por ejemplo “¿Cuál fue el motivo por el que la ferrería tradicional prolongó su presencia hasta fines del siglo XIX cuando ya se hallaba condenada tecnológicamente desde, por lo menos, cien años atrás?” y reconoce que “...algunas de las principales referencias documentales o de la obra de eruditos han sido repetidas y parafraseadas hasta la saciedad. En ocasiones se han arrastrado errores..." 37 . La mayor parte de los autores que se han ocupado del tema han insistido en la crisis del sector desde finales del siglo XVIII. Los factores aducidos irían desde la política aduanera (decretos de 1779 y 1784), las guerras, la competencia del hierro europeo, pasando por el atraso tecnológico e incompetencia técnica, el encarecimiento de las materias primas o la dependencia de un mercado protegido ${ }^{38}$.

36 ODRIOZOLA OYARBIDE, L.: La construcción naval en el País Vasco, siglos XVI-XIX. Evolución y análisis comparativo, Donostia, Diputación Foral de Gipuzkoa, 2002, p. 208.

37 LEGORBURU FAUS, E.: Op. cit., pp. 129-134, 166-167, 207.

38 BARCENILLA, M.A.: La pequeña Manchester. Origen y consolidación de un núcleo industrial guipuzcoano. Errentería (1845-1905), Donostia, Diputación Foral de Gipuzkoa, 1999, pp. 101-102. 
Sin embargo, en el caso del encarecimiento de las materias primas se deben hacer una serie de puntualizaciones. Es imprescindible hacer notar que durante el siglo XVIII y a principios del siglo XIX todavía la situación del bosque no era catastrófica. En primer lugar, no se debe desdeñar el hecho, pocas veces recordado, de que en las primeras décadas del siglo XIX se recogieron los frutos de la labor de reforestación que se venía desarrollando desde mediados del XVIII (seis millones de árboles jóvenes en 1784), lo cual haría contar con árboles ceduos de grandes dimensiones, que aportarían grandes cantidades de leña, aunque la superficie forestal fuese menor. El retroceso de la masa forestal no tiene porqué significar menos cantidad de leña; puede haber menos árboles pero de mayores dimensiones o que produzcan más leña. Más aun teniendo en cuenta que a partir del siglo XVIII se generalizó en toda Guipúzcoa el uso de la técnicas de la entresaca y del trasmochado o desmochado, en sus dos vertientes -guiado y no guiado-, en detrimento de la técnica del jaral, lo que aumentó la productividad de los árboles por unidad de explotación, porque, por un lado, permitió reducir el tiempo de espera entre corte y corte -de los doce o quince años que se empleaban en el caso de los jarales se pasó a los ocho o diez años-, y, por otro, facilitó la ampliación de las dimensiones y magnitud del árbol, cuyas ramas, gracias al guiado, crecían en altura y extensión, dando lugar a mayores cantidades de leña ${ }^{39}$.

En segundo lugar, hay que tener en cuenta que Guipúzcoa contaba todavía con importantes extensiones de hayedo, cuya explotación masiva no se inició hasta finales del siglo XVIII, como demuestran el caso de la Parzonería de Álava y Guipúzcoa, donde hasta 1785 no se había utilizado nunca la técnica de entresaca, pues se practicaba únicamente el trasmocho y la tala por el pie, sin atender a la edad del árbol, o el ejemplo de los montes concejiles de Ataun, en los que las hayas no empezaron a ser repobladas hasta finales del XVIII, momento hasta el que su explotación estuvo principalmente orientada a la producción y exportación de remos ${ }^{40}$. La explotación de leña de haya para la fabricación de carbón vegetal, con ser habitual, no sería generalizada hasta el siglo XIX, pues la leña de haya es de menor calidad que la de roble -junto al castaño, la más repoblada- y su extracción supone mayores gastos de transporte, al situarse sus arboledas en las zonas altas, por encima del piso colino, bastante alejadas de las ferrerías, que buscan los cauces de los ríos en los fondos de valle.

En tercer lugar, se debe ponderar la importante aportación de leña y carbón, además de madera -principalmente de haya-, procedente de los ricos y abundantes bosques alaveses y navarros, que, ya desde finales del siglo XVII, pero sobre todo desde finales del siglo XVIII y durante todo el siglo XIX, supusieron una fuente de recursos esencial para saciar las necesidades de las ferrerías guipuzcoanas, principalmente de las situadas

39 ARAGÓN RUANO, A.: Op. cit., pp. 66 y 78.

40 ARAGÓN RUANO, A.: Op. cit., pp. 41-43. 
en localidades limítrofes a los mencionados territorios, pero también de las enclavadas en todo el territorio guipuzcoano. Ya en 1658 la Parzonería de Guipúzcoa, compuesta por Segura, Cegama, Cerain e Idiazábal se quejaba ante el Consejo Real de la actitud mantenida por la de Álava. Estando los montes de la Parzonería de Álava y Guipúzcoa en sazón para ser cortados, se juntaron todos los parzoneros para acordar la venta de los montes, nombrar examinadores, señaladores y divididores, pero los representantes de Salvatierra y San Millán no quisieron acudir, quejándose de que la venta provocaría un doble perjuicio: por un lado, dejaría sin albergue a sus ganados y, por otro, se vendería por un valor menor al real, que ascendía a unos 40.000 ducados, al ser los ferrones guipuzcoanos los únicos compradores, y dejaría sin auxilio ni madera a sus vecinos para el reparo de edificios. Salvatierra exigía que únicamente se llevase a cabo la venta de aquellas porciones menos apropiadas para la extracción de madera para edificar y para el albergue de ganado, y que, en aquellas, las porciones más importantes no se talasen sino que se trasmochasen, para de esa forma garantizar dichos aprovechamientos ${ }^{41}$. En la encuesta realizada por la Provincia de Guipúzcoa en 1784 en la Parzonería de Álava y Guipúzcoa existían unos 76.513 árboles, 15.669 en Guipúzcoa y 60.844 en Álava, lo cual demuestra que las parzonerías alavesas venían siendo explotadas con menor intensidad y contaban con una mayor riqueza forestal que las guipuzcoanas ${ }^{42}$.

Tabla 5: Precio de la leña para carbón (1530-1810) (maravedís/carga)

\begin{tabular}{|c|c|c|c|c|c|c|}
\hline AÑOS & Fuenterrabía & Asteasu & Legazpia & Cestona & Irún & Ataun \\
\hline 1530 & 16 & 7,7 & & & & \\
\hline 1540 & & 6 & 17,6 & 30 & & \\
\hline 1550 & & 6 & & 36,75 & & \\
\hline 1560 & 34 & & 31 & 32 & & 7,5 \\
\hline 1570 & 46,75 & & 17 & 43 & & \\
\hline 1580 & 34 & 27,3 & 17 & 37,87 & & \\
\hline 1590 & 34 & & 51 & 48,75 & & \\
\hline 1600 & 34 & 20,12 & 17 & 39,25 & & \\
\hline 1610 & 59,5 & 48 & 38,25 & 65,5 & & 27 \\
\hline 1620 & 51 & 29,75 & 234,6 & & & 35,625 \\
\hline 1630 & 59,5 & 36,83 & 48,16 & 34 & & 45,375 \\
\hline 1640 & 53,12 & 119 & 35,5 & 68 & & 28,5 \\
\hline 1650 & 82,62 & 30,08 & 51 & & & 27 \\
\hline 1660 & 82,62 & & & & & \\
\hline 1670 & 139,74 & & & & & \\
\hline 1680 & 141,27 & 82,5 & & 85 & & 32 \\
\hline 1690 & 76,5 & & & 147,33 & & 24 \\
\hline 1700 & 82,875 & 51 & 46,5 & & & 32 \\
\hline 1710 & 51 & & 56 & 51 & & 46,5 \\
\hline 1720 & 76,5 & & 42,5 & 64 & & \\
\hline 1730 & 108,375 & 190,5 & 53 & 85 & & \\
\hline 1740 & 114,75 & 124,5 & 68 & 64 & & \\
\hline 1750 & 121,125 & 106 & 68 & & & \\
\hline
\end{tabular}

41 A.H.N., Consejos Suprimidos. Escribanía de Escariche, L 23804 / Exp 2.

42 A. Parz., B, 3, 1, 3. 
Retroceso forestal, desamortizaciones y atraso tecnológico en la industria guipuzcoana del hierro durante el Antiguo Régimen

\begin{tabular}{|c|c|c|c|c|c|c|}
\hline 1760 & 157,25 & 161,5 & 119 & 204 & 255 & 61,6 \\
\hline 1770 & 282,375 & 204 & 136 & 195,5 & 264,84 & 60,83 \\
\hline 1780 & 255 & 204 & & & & 69,5 \\
\hline 1781 & & 187 & & & & 86 \\
\hline 1782 & 256,5 & 204 & & 243,875 & & 74 \\
\hline 1783 & 255 & 255 & & 295,3 & & \\
\hline 1784 & 267,75 & 235 & & 272 & & 102 \\
\hline 1785 & & 238 & & 318,66 & & \\
\hline 1786 & & 255 & & 306 & & \\
\hline 1787 & & 216,75 & & & & \\
\hline 1788 & & 229,5 & & 308,33 & & 94 \\
\hline 1789 & 382,5 & & & 312 & 259,25 & \\
\hline 1790 & 408 & 280,5 & & 256 & 351,53 & 106,25 \\
\hline 1791 & 429,75 & & & 297 & & 102 \\
\hline 1792 & 388,5 & & & 276,6 & & \\
\hline 1793 & 578 & 312,5 & & 289 & & \\
\hline 1794 & & & & 239,71 & & 102 \\
\hline 1795 & 408 & & & & & \\
\hline 1796 & 226,6 & & 187 & 292,2 & & \\
\hline 1797 & & 221 & 187 & 246,5 & & 110,5 \\
\hline 1798 & 382,6 & 221 & & & & 68 \\
\hline 1799 & & & & 272 & 238 & \\
\hline 1800 & & & & 332,2 & & \\
\hline 1801 & 270,9 & & 178,5 & 246,5 & 152,25 & \\
\hline 1802 & 318,75 & 255 & 187 & 332,81 & 316,5 & 119 \\
\hline 1803 & 417 & & 187 & 314,5 & 348,5 & 110,5 \\
\hline 1804 & 538,5 & 306 & 187 & & 444,125 & 136 \\
\hline 1805 & & & 187 & 350,25 & 297,5 & \\
\hline 1806 & & 374 & 187 & 364,5 & 204 & 136 \\
\hline 1807 & & 136 & 204 & 374 & & \\
\hline 1808 & & & 204 & 443,75 & & \\
\hline 1809 & & & 170 & 306 & 123 & \\
\hline 1810 & & & & 306 & & \\
\hline
\end{tabular}

Fuente: ARAGÓN RUANO, A.: El bosque guipuzcoano...Op. Cit., pp. 127-135, 237-247.

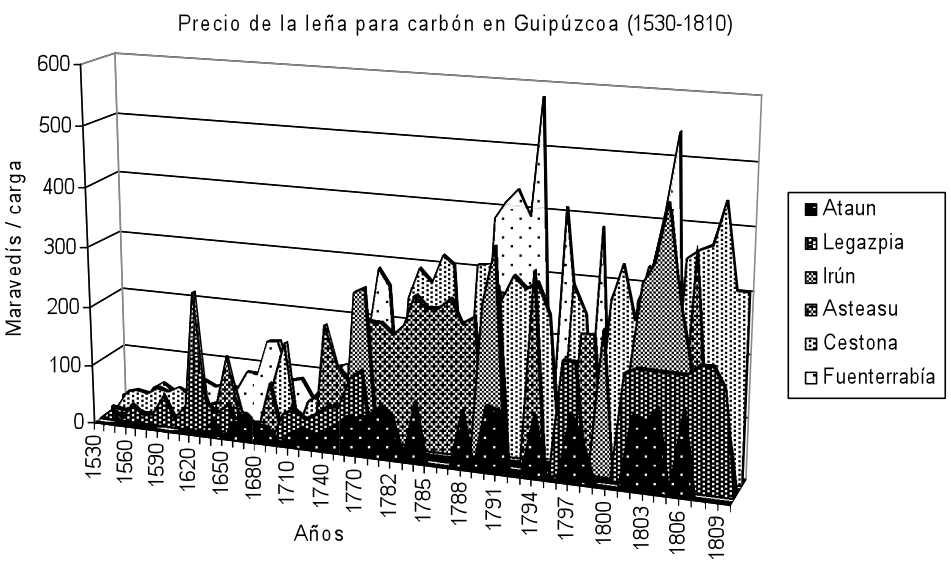

Fuente: elaboración propia apartirde ARAGÓN RUANO, A.: Op. cit., pp.237-247. 
Los precios de la leña para carbón se mantuvieron más bien bajos y a precios competitivos a partir de comienzos del siglo XIX, lo que permitió a las instalaciones ferronas mantener su cuota de mercado. Las medias de los precios de todas las ventas registradas cada diez años -los datos comprendidos entre 1780 y 1810 son datos anuales-, que aparecen reflejadas en la tabla 5 y el gráfico inferior, demuestran que el precio de la leña para carbón se mantuvo a niveles muy bajos y estables hasta la década de los años sesenta del siglo XVIII, cuando la demanda de productos forestales para la Corona y la construcción naval, y la aplicación de la Ordenanza de Montes de 1749 se hicieron notar y rompieron con la política de algunos municipios favorable a los intereses siderúrgicos -por otro lado, muy bien representados en las instituciones locales y provinciales guipuzcoanas- basada en el derecho de tanteo y la fosilización del precio del carbón en leña en torno a 1,5 reales $^{43}$. A partir de ese momento, aunque con oscilaciones, se puede apreciar que los precios se mantienen en la mayoría de los casos por encima de los 100 maravedís o 3 reales, llegando incluso hasta los 538 maravedís o 15 reales. El punto álgido se produce sintomáticamente hacia finales del siglo XVIII y principios del siglo XIX, coincidiendo con un proceso de inflación de los precios que se da en toda Europa. Pero curiosamente, tras el desastre de Trafalgar y la invasión francesa los precios vuelven a descender, manteniéndose en niveles relativamente bajos durante todo el siglo XIX. Es decir, el aumento de la demanda de madera para la construcción de mercantes para la Real Compañía de Caracas y de reales bajeles para la Armada Real introdujo en el mercado un factor de distorsión, al aumentar la presión sobre las cada vez más limitadas reservas de madera, cuyo efecto más claro fue el aumento brusco del precio de la carga de leña para carbón. Sin embargo, la desaparición del mismo factor, volvió a liberar las reservas de madera y leña, lo que conllevó un descenso de los precios.

En el caso de Rentería, estudiado por Barcenilla ${ }^{44}$ y expresado en la siguiente tabla, tenemos una tónica similar, a pesar de lo puntual de los datos, que confirma que el precio de la carga de leña para carbón descendió con el cambio de siglo, manteniéndose bajo hasta la década de los años cincuenta del siglo XIX, momento en el que volvió a experimentar un repunte.

Tabla 6: Precios de la carga de leña en Rentería (1819-1855)

\begin{tabular}{|c|c|c|c|}
\hline Año & Precio & Año & Precio \\
\hline 1819 & 8 reales & 1851 & 20 reales \\
\hline 1845 & 7 reales y 1 cuartillo & 1852 & 15,5 reales \\
\hline 1848 & 4 reales & 1855 & 19,5 reales \\
\hline 1849 & $8,75-13$ reales & 1861 & 17 reales \\
\hline
\end{tabular}

43 ARAGÓN RUANO, A.: Op. cit., pp. 127-134

44 BARCENILLA, M. A.: Op. Cit., pp. 101-102. 
Un comportamiento similar se da también en el caso vizcaíno, aunque los precios máximos son considerablemente menores que los guipuzcoanos, pues jamás superan los 7 reales. Por ejemplo, en Arrieta los precios de la leña llegan hasta los niveles más elevados en la década final del siglo XVIII y primera década del siglo XIX, para en las décadas posteriores sufrir un pronunciado descenso. Por su parte, en Valmaseda las máximas se alcanzan hacia los años ochenta del siglo XVIII, para desde entonces descender ininterrumpidamente ${ }^{45}$.

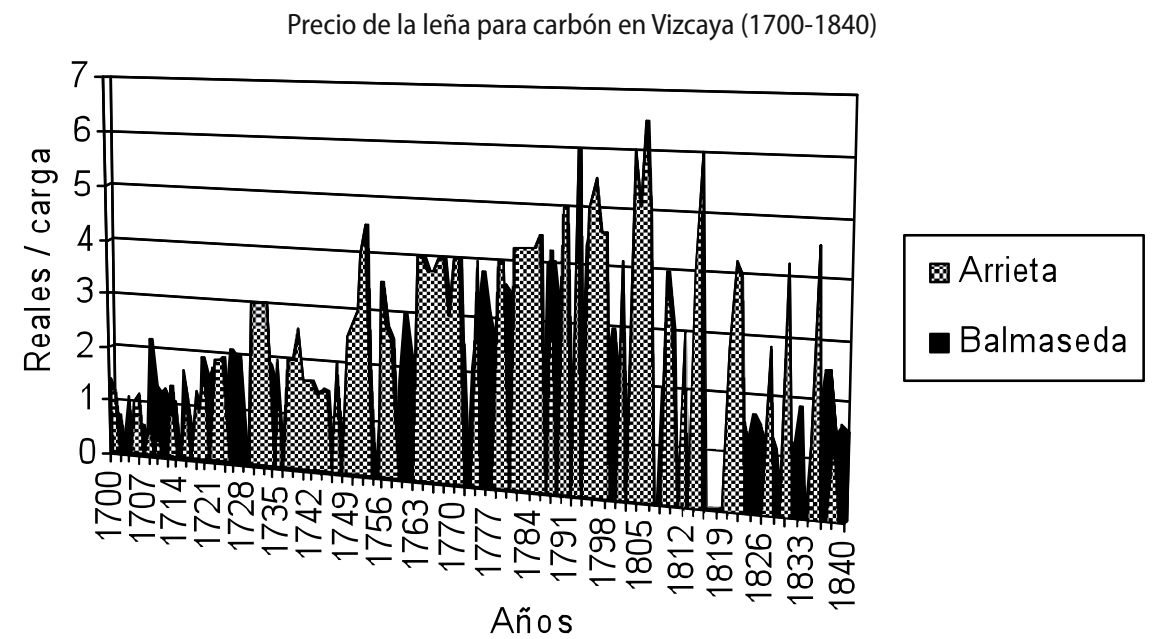

Fuente: elaboración propia a partir de los datos aportados por URIARTE AYO, R.: Op. cit.

Si bien Rafael Uriarte Ayo asevera que el precio del hierro condicionaba el precio de la leña, vinculando su descenso de fines del siglo XVIII con las dificultades del sector siderúrgico, en nuestra opinión existen otra serie de factores que influyen en el precio de la leña, como pueden ser la mayor o menor extensión de la masa arbórea disponible en cada jurisdicción y en los territorios limítrofes, la demanda de la construcción naval, el consumo doméstico, las necesidades de los concejos quienes establecían los precios de salida en las subastas, etc. Este mismo autor asegura que, con la mencionada caída y el consiguiente descenso de los precios de la leña, los incentivos desaparecieron, favoreciendo así los desmontes, las talas apresuradas y con ello la reducción de la masa forestal, que acentuaron aún más el hundimiento de los precios forestales. En nuestra opinión, la bajada repentina y drástica de los precios de la leña se produjo precisamente por la desvinculación que sufrieron los bosques y montes concejiles, que pasaron a manos de particulares, la mayoría de los cuales

45 URIARTE AYO, R.: Op. cit., pp. 127-130. 
tenían importantes inversiones o eran dueños de ferrerías. Como ya se ha adelantado, la presión de la demanda de la Armada Real -y en menor medida la de la Real Compañía de Caracas y la Real Compañía de Filipinas-, y su disputa con los intereses de las de las ferrerías, causa del aumento del precio de la leña, sintomáticamente desde 1750 hasta 1808, desapareció tras el desastre de Trafalgar y con la ocupación francesa -que supusieron, entre otras cuestiones, la extinción del férreo control y la supervisión de las autoridades de Marina ${ }^{46}$ - aunque la construcción naval mercante siguió siendo un sector dinámico. El colapso al que había llegado la disponibilidad de materia prima, sólo se pudo resolver con la introducción en el mercado de grandes extensiones de bosque que hasta ese momento había permanecido en manos muertas, esto y el miedo a perder sus nuevas adquisiciones, de ocurrir un cambio político, llevó a una gran cantidad de nuevos propietarios a talar sus nuevas propiedades ${ }^{47}$, con lo que inundaron el mercado de leña, lo cual provocó el descenso lógico del precio del producto y garantizó el mantenimiento rentable de las ferrerías.

Ésta es la clave -además del régimen de propiedad ${ }^{48}$ - para entender el estancamiento tecnológico de la industria ferrona guipuzcoana -y tal vez de la vizcaina-: el control que los intereses ferrones ejercían sobre el bosque y la leña, gracias a su preeminencia en las instituciones locales -y provinciales- o a su peso específico en la economía, permitió mantener barata la materia prima y, con ello, los costos de producción -aunque subiesen los salarios o el precio de la vena-, lo que hizo innecesaria la introducción de mejoras tecnológicas significativas, y permitió que el hierro guipuzcoano siguiese siendo competitivo. Al respecto son muy clarificadoras las palabras del Superintendente de plantíos y navíos, don Martín de Olózaga y Espilla, quien en informe enviado a la Corona desde San Sebastián el 18 de agosto de 1723, en respuesta a algunas informaciones que apuntan a que ante la escasez de madera la carga de carbón había

46 Sobre lo que autores, como Ofelia Rey Castelao, consideran una expropiación del arbolado por parte de la Corona y una limitación considerable de los usos del suelo, que dio lugar a una importante conflictividad en toda la Península ibérica, son de obligada lectura las síntesis de la mencionada autora. REY CASTELAO, O.: "La propiedad colectiva en la España Moderna", Stvdia Histórica, 16, 1997, pp. 5-16 e Idem: "Montes, bosques y zonas comunales: aprovechamientos agrícola-ganaderos, forestales y cinegéticos", en ARANDA PÉREZ, F. J. (Coord.): El mundo rural en la España Moderna. Actas de la VII Reunión Científica de la Fundación Española de Historia Moderna, Cuenca, Universidad de Castilla-La Mancha, 2004, pp. 907-964. Para el caso guipuzcoano véase ARAGÓN RUANO, A.: El bosque guipuzcoano...Op. cit e Idem: "La conflictividad en torno al bosque guipuzcoano en la Edad Moderna: recorte y apropiación de los usos y bienes concejiles”, en ARANDA PÉREZ, F. J. (Coord.): Op. cit., pp. 979-997.

47 OTAEGUI ARIZMENDI, A.: Guerra y crisis de la hacienda local...Op. cit., pp. 140-142 y A.G.G.-G.A.O., CO LCI 5027.

48 ALBERDI LONBIDE, X.: "Proyecto de Compañía de comercialización del hierro a principios del siglo XVIII", en Historia de Oñati: siglos XIV-XIX, Oñati, 1999, pp. 159-179. 
pasado de 1,5 a 5,5 reales y el quintal de hierro de 40 a 80 reales, daba algunas de las claves de la estructura empresarial y comercial del hierro guipuzcoano:

“...Las ferrerias suelen estar, o, no corrientes según los caudales de sus dueños que lo necesitan promto para anticipar el verano muchas prevenciones para trabaxarse el invierno, y tambien consiste en si son buenos Administradores de esta su Hacienda como sucede en las de otras cualquiera calidad; se ha de andar muchas Provincias, o, lo mas de el Reyno para hallarse las ciento y sessenta ferrerias que sienta estar cerradas; en esta de Guipúzcoa, se encontraran en este estado unas veinte no por carestía de carbon sino por alguna de las caussas expresadas y no menos por el precio tan infimo que en muchos años ha tenido el fierro, y lo comprueva haver redificadose últimamente cinco, o, seis ferrerias, porque el quintal mayor vale ya sessenta Reales de vellon, y nunca se ha oido el de los ochenta que dize ni jamas ha llegado a los settenta; este precio de las sessenta Reales que ha alentado a redificar es por las muchas cantidades que demas de las que para Yndias siempre embian los vasallos a la Andaluzia lo llevan estos ultimos años los franceses para su uso comun y para la nueva colonia de Mississipi que han establecido en la costa de la Nueva España y para la navegación que han tenido al Mar del Sur; Y tambien los Yngleses que tienen el asiento de la Guinea y que navegan por toda la America lo llevan en grandes partidas; y ha concurrido mucho consumo en la clavason necesaria para los seis vaxeles que el año 1716 se construyeron en estos astilleros por quenta de su majestad y para los otros seis que en los mismos empezaron ahora cinco años, y aun se ha transportado a Cadiz la clavazón correspondiente a dos vaxeles que han de construyrse en la Havana; y nadie ignora que cualesquiera generos los abarata el poco consumo y que los encarece el concurso de muchos compradores como estos tiempos ultimos los ay." ${ }^{\prime 4}$.

El problema llegó ya hacia 1730, cuando surgió con gran fuerza la demanda de madera para la construcción naval, primero a través de la Real Compañía de Caracas -principal impulsora del Reglamento de Montes de 1738- y después, desde 1749, a través de la Real Armada ${ }^{50}$. Ello exigió la introducción de más materia prima en el mercado, ante la nueva demanda, lo que permitió a los concejos obtener mayores rendimientos -es claro el caso de San Sebastián o Urnieta, frente a Hernani-; además de la demanda procedente de la construcción naval, fueron el precio del hierro, la demanda de la construcción de edificios, el crecimiento de la población (leña para

49 Archivo Histórico Nacional (A.H.N.), Consejos 10859.

50 Significativamente, el precio del hierro en Guipúzcoa subió entre 1710 y 1730, bajó entre 1735 y 1745, y volvió a subir a partir de 1750. CARRIÓN, I.: "Los precios del hierro en Guipúzcoa durante los siglos XVII y XVIII: un buen indicador de la coyuntura del sector siderúrgico", Revista de Historia Económica, n 3, (1991), pp. 481-498. 
cocinas y madera para casas), la demanda de la barriquería ${ }^{51}$, coincidiendo con un momento de auge de los caldos navarros y riojanos, las expectativas financieras de los concejos y el retroceso progresivo del bosque los factores que provocaron el aumento del precio de la leña, hasta aproximadamente $1805^{52}$; aumento que a partir de entonces puso en peligro la rentabilidad de las ferrerías, pero que ni mucho menos acabó con ellas ${ }^{53}$. De esta forma, los beneficios de la industria ferrona comenzaron a descender, con lo que los dueños de ferrerías aparentemente perdieron interés por la explotación de los bosques y se permitieron el lujo de no comprar leña en sus jurisdicciones -abasteciéndose desde otras localidades y provincias-, lo que, en ocasiones, obligó a los concejos a bajar los precios -que era la verdadera intención de la maniobra de los mencionados dueños de ferrerías- ${ }^{54}$.

Así mismo ante la pérdida de rentabilidad de los bosques, los concejos optaron por vender esos terrenos para saldar sus deudas, muchas de ellas contraídas con sus propios concejantes, viveristas y dueños de ferrerías. Cuando los nuevos dueños las adquirieron, se apresuraron a cortar toda la leña y madera, y venderla ${ }^{55}$, inundando el mercado de madera y leña, con lo que, a partir del período 1805-1810, bajaron nuevamente los precios de la leña ${ }^{56}$. En Guipúzcoa el vacío de poder provocado por la inva-

51 En 1724 la polémica surgió en los montes de Altube, Aramayona y la frontera con Guipúzcoa, donde don Antonio de Gaztañeta, por encargo real, pretendía cortar 500 árboles para la fábrica de varios barcos, porque muchos comerciantes talaban los mejores árboles, reduciéndolos a duelas para exportar a Francia y Holanda para pipería de navíos, y a carbón para ferrerías. Ante ello, Luis I y Felipe V expidieron ese mismo año sendas Reales Órdenes prohibiendo la tala de los montes si no era para la construcción naval. A.H.N., Consejos 10859.

52 También parecen tener la misma tendencia los precios en Vizcaya; véase LANGE, J.: Economía rural tradicional en un valle vasco. Sobre el desarrollo de estructuras mercantiles en Zeberio en el siglo XVIII, Bilbao, Beitia, 1996, p. 241.

53 No parece que los datos aportados por Carrión, quien habla de "largo declive", "gravedad de la crisis" o de "grave crisis" a partir de la década de los ochenta, nos muestren tal situación: en 1752, se producían 4.391 Toneladas métricas de hierro (Tm); en 1784, 5.018 Tm; en 1789, 4.428 Tm (ambos datos aportados por Bilbao y Fernández de Pinedo, que el mencionado autor comparte); en 1799, 3.241 $\mathrm{Tm}$; y en 1802, $4.600 \mathrm{Tm}$. A la luz de estos datos es impensable hablar de una profunda o grave crisis de la siderurgia guipuzcoana a finales del siglo XVIII y principios del XIX. CARRIÓN, I.: La siderurgia guipuzcoana en el siglo XVIII, Bilbao, UPV, 1991, pp. 124, 265, 283-286. De todas formas, es éste un aspecto que sin duda precisa de una profunda revisión historiográfica.

54 Coincidiendo con esta coyuntura, los propietarios de las ferrerías iniciaron prospecciones para la localización y explotación de minas de carbón mineral; concretamente, en 1804 se localizaron dos en el término de Aya. A.G.G-G.A.O., JD IM 2/20/38. Acerca de quienes fueron los impulsores de las mismas, Madoz señala que en 1807 fueron el Conde de Villafuertes, el de Peñaflorida y don Antonio del Corral, señor de Zarauz, propietarios de numerosas ferrerías, los que comenzaron a explotar una mina de carbón situada en el barrio de Urteta de Zarauz. MADOZ, P.: Diccionario geográfico-estadístico-histórico de España y sus posesiones de Ultramar (Gipuzkoa), Madrid, 1845-1850 (Facsimil, San Sebastián, 1991), p. 257.

55 OTAEGUI ARIZMENDI, A.: Guerra y crisis de la hacienda local... Op. cit., pp. 140-142.

56 En el caso vizcaíno, concretamente en el de Líbano de Arrieta, se aprecia cómo los precios siguieron subiendo y se mantuvieron altos hasta 1810 -como en Guipúzcoa-, fecha en la que el precio bajó hasta 1829 -aunque manteniendo un nivel alto-, momento en el que volvieron a subir, pero sin alcanzar los niveles anteriores. GOGEASCOECHEA, A.: Op. cit., 1993, p. 189. 
sión francesa permitió una gran cantidad de talas ilegales, de las que se quejaban las autoridades locales. Más aún, aprovechando que Fernando VII no llegaría hasta marzo de 1814 de su destierro de Valenciennes y que las tropas francesas estaban prácticamente derrotadas, las Juntas Generales de Guipúzcoa autorizaron a los pueblos a reintegrar en terrenos concejiles las deudas que tenían con particulares (viveristas y acreedores), sin la pertinente licencia o beneplácito real -imprescindible hasta la fecha- ${ }^{57}$.

Por tanto, el abaratamiento de la materia prima es lo que hizo que muchas ferrerías vascas se mantuviesen, bajo un modelo arcaico, hasta la década de los años ochenta del siglo XIX. Las ferrerías guipuzcoanas mantuvieron un modelo arcaico porque de momento no necesitaron renovarlo, ya que contaban con leña barata, que reducía los costes de producción y las hacía competitivas. Aunque a largo plazo las sucesivas desamortizaciones y la expansión agrícola y ganadera hipotecaron el futuro de la riqueza forestal guipuzcoana, a corto plazo pusieron en manos de los ferrones nuevas cantidades de madera y leña a precios competitivos, que hicieron que la actividad siderúrgica siguiese siendo una de las principales, si no la principal, actividad económica de Guipúzcoa, al menos hasta mediados del siglo XIX. Pascual Madoz en su Diccionario geográfico-estadístico-histórico, hablaba entre 1845 y 1850 de que " $E l$ comercio del hierro aportará próximamente al país 4.000.000 de reales en cada año, lo cual nos hace considerar a la ferreria como el ramo principal de industria a que el gobierno y las autoridades locales deben prestar una muy preferente atención.".

Es así como las ferrerías mantuvieron su viabilidad y rentabilidad, lo que las hizo perdurar hasta finales del siglo XIX: si bien, entre 1808 y 1839, parece que hubo un declive coyuntural provocado por la Guerra de la Independencia y la Guerra Carlista, según Pascual Madoz, la siderurgia se recuperó ya en 1841, fecha en la que 39 ferrerías de Guipúzcoa producían unos 3.248 Tm, que suponían una media de 83,20 Tm por ferrería, lo cual significa un rendimiento o productividad por unidad de producción superior al alcanzado durante los mejores momentos del XVIII, y no muy alejado del mejor de fines del siglo XV. Entre 1845 y 1850 el número de factorías aumentó hasta las 51 ferrerías, que seguían abasteciendo el mercado español y americano, con una producción de unas 216.000 arrobas de hierro, es decir, 2.484 Tm. Si las comparamos con las 4.391 Tm que Carrión calcula que producían las 73 ferrerías existentes entre 1752, supondría una producción de unas 49 Tm por ferrería en 1845-1850, frente a las 60 Tm por ferrería en 1752, muy superior a la producción de las 141 ferrerías vizcaínas, que en total suponían, según este mismo autor, 5.148 Tm, esto es, 36,5 Tm por ferrería, lo cual convertía a las ferrerías guipuzcoanas en un factor económico importante que ocupaba, según el mismo autor, en un momento

57 ARAGÓN RUANO, A.: Op. cit., pp. 93-94. 
en el que Guipúzcoa contaba con 141.752 habitantes, a un total de 10.200 personas directamente, esto es, entre un 7 y un $10 \%$ de la población ${ }^{58}$.

Tabla 7: Producción de hierro y consumo forestal de las ferrerías guipuzcoanas (siglos XV-XIX)

\begin{tabular}{|c|c|c|c|c|}
\hline Período & Número de ferrerías & $\begin{array}{c}\text { Hectáreas de bosque } \\
\text { consumidas anualmentef }\end{array}$ & $\begin{array}{l}\text { Toneladas métricas } \\
\text { producidas anualmente }\end{array}$ & $\begin{array}{c}\text { Toneladas métricas } \\
\text { producidas anualmente } \\
\text { por cada ferrería }\end{array}$ \\
\hline Fines del siglo XVa & 110 & 550 hectáreas & $10.147 \mathrm{Tm}$ & $92 \mathrm{Tm}$ \\
\hline 1548a, b & 117 & 585 hectáreas & $14.625 \mathrm{Tm}$ & $125 \mathrm{Tm}$ \\
\hline $1581 b$ & 180 & 800 hectáreas & $20.000 \mathrm{Tm}$ & $111,1 \mathrm{Tm}$ \\
\hline $1625 b$ & 188 & 752 hectáreas & $18.800 \mathrm{Tm}$ & $100 \mathrm{Tm}$ \\
\hline $1752 b, c$ & 73 & 175,6 hectáreas & $4.391 \mathrm{Tm}$ & $60 \mathrm{Tm}$ \\
\hline $1784 c$ & & 200,7 hectáreas & $5.018 \mathrm{Tm}$ & \\
\hline $1789 e$ & 64 & 177 hectáreas & $4.428 \mathrm{Tm}$ & $69,18 \mathrm{Tm}$ \\
\hline $1799 c$ & & 129,6 hectáreas & $3.241 \mathrm{Tm}$ & \\
\hline $1802 c$ & & 184 hectáreas & $4.600 \mathrm{Tm}$ & \\
\hline 1841d & 39 & 130 hectáreas & $3.248 \mathrm{Tm}$ & $83 \mathrm{Tm}$ \\
\hline $1845-1850 d$ & 51 & 99,36 hectáreas & $2.484 \mathrm{Tm}$ & $49 \mathrm{Tm}$ \\
\hline $1850 \mathrm{e}$ & 58 & 238 hectáreas & $5.950,8 \mathrm{Tm}$ & $102,6 \mathrm{Tm}$ \\
\hline $1864 \mathrm{e}$ & 20 & & & \\
\hline 1871 e & 9 & 25,7 hectáreas & $642,6 \mathrm{Tm}$ & 71,4 Tm \\
\hline 1881e & 4 & & & \\
\hline
\end{tabular}

Fuente: (e) BARCENILLA, M.A.: Op. cit, pp. 101-102; (c) CARRIÓN ARREGUI, I.M.: La Siderurgia Guipuzcoana en el siglo XVIII...Op. cit., 1991, p. 124, 265, 266, 283-286; (a) DÍEZ DE SALAZAR, L.M.: Op. cit., pp. 146 y 273; (b) FERNÁNDEZ ALBALADEJO, P.: Op. cit., p. 60; (d) MADOZ, P. Op. cit., p. 68. (f) Se ha tomado como referencia la equivalencia llevada a cabo por Díez de Salazar, por la que la producción de 1 quintal de hierro suponían el consumo de 12 cargas de leña, esto es, para fabricar $1 \mathrm{Tm}$ de hierro hacían falta 0,04 hectáreas de bosque.

Si bien es indudable el descenso de la producción en términos globales, como en todo momento de reajuste a las necesidades del mercado, se produce una reconversión y reorganización del mismo, de forma que quedan los más fuertes y competitivos, mientras que los más débiles desaparecen. Los que sobreviven conservan la cuota de mercado y aumentan su productividad y rendimientos. El mercado y la producción global se van reduciendo, tras el auge experimentado entre 1752 y 1784, para los hierros guipuzcoanos, pero las ferrerías más fuertes y dinámicas consiguen sobrevivir dignamente, porque mantienen una producción particular que las hace rentables. Según Luis María Bilbao, el fin de las pluriseculares ferrerías era predecible y sólo lograron resistir por "algún tiempo" las mejor situadas al pie de importantes riquezas forestales y a distancia de los grandes centros productores modernos. Entre la alternativa de la fundición de los altos hornos con carbón fósil o de madera, la siderurgia vasca optó mayoritariamente y por un tiempo por el combustible tradicional, porque era económicamente el más viable, mientras no se modificaran las disponibilidades del país 
en carbón mineral ${ }^{59}$. Es decir, la riqueza forestal del país, a pesar de estar muy dañada, seguía teniendo capacidad para abastecer a las ferrerías tradicionales que pervivían, pero también a las nuevas instalaciones que seguían utilizando el carbón vegetal.

En el caso de la ferrería de Añarbe, abierta y en funcionamiento hasta 1881, ésta aumentó su rango productivo cuando el conjunto del sector pasaba sus momentos más difíciles, tal vez porque absorbió parte del mercado liberado por las que cerraban sus puertas. En 1844 producía 187,3 Tm y en 1862 en la ferrería trabajaban 203 días al año y 24 horas al día, lo cual suponía una producción de 151,8 Tm anuales. En definitiva, la producción estaría entre 149,6 y 187 Tm. En 1817, 1818 y 1834 consumía 10.000 cargas de carbón, aunque un informe de 1850 le atribuía una capacidad de 7 u 8.000 cargas anuales. Barcenilla vincula la permanencia de Añarbe en activo a la buena conservación del bosque -lo que le permitió mantener una elevada capacidad energética- y a la persistencia de un segmento de la demanda interior de hierro de excelente calidad protegido por medio de aranceles ${ }^{60}$.

W. Strassman matiza el concepto que generalmente se utiliza para definir el "anacronismo", señalando que el producto de los modos arcaicos puede convivir armónicamente con el de los modernos, incluso evolucionar al alza en términos absolutos $^{61}$. Luis María Bilbao habla de crisis general de la siderurgia vasca, aunque la división en tres fases que hace de la modernización de la misma -un fuerte retroceso en el arranque, una corta transición de unos 30 años y una relativa rapidez en la adopción de la moderna industria del acero-, sugiere más bien la existencia de un verdadero proceso de adaptación. Como explica este autor, la demanda específica de un mercado dado reclama una precisa orientación de la producción hacia un tipo de producto concreto, lo cual sólo resultará viable mediando unas determinadas tecnologías, de entre las que se escogerán las más apropiadas económicamente en función de los recursos físicos y financieros disponibles. Según el mismo autor, la escasa demanda española hasta 1848 no hace rentable un alto horno ${ }^{62}$.

Según Luis María Bilbao, en contraste con Gran Bretaña, donde el pudelado se introdujo más de medio siglo después de la fusión con coque, los países del continente aprendieron primero las técnicas del pudelado y laminado, manteniendo entre tanto sus fundiciones al carbón vegetal e importando como "materia primas" lingote

59 BILBAO BILBAO, L. M.: "La primera etapa de la industrialización en el País Vasco, 18001880: cambio tecnológico y estructura de la industria siderúrgica", en FERNÁNDEZ DE PINEDO, E.HERNÁNDEZ MARCO, J. L. (Ed.): La industrialización del norte de España. Barcelona, Crítica, 1988, pp. 243-245.

60 BARCENILLA, M. A: Op. cit., pp. 63 y 105.

61 LEGORBURU FAUS, E.: Op. cit., pp. 156-159.

62 BILBAO BILBAO, L.M.: "La primera etapa...Op. cit., p. 237. 
inglés -también belga- para afinarlo en las propias industrias nacionales. La experiencia vasca encontró en el modelo continental un punto de referencia tipológico más próximo. La modernización del sector no fue improvisada, sino que recogía los frutos de un proceso dilatado, que se abrió en el siglo XVIII y discurrió por caminos diferentes. Unos siguieron pautas meramente "reformistas" de la tecnología más tradicional, como la mejora de las instalaciones de las viejas forjas o la mecanización de ciertos ramos ligeros de la siderurgia, mediante el modelo de la fandería. Otros avances más "revolucionarios" se orientaron a relabrar los tochos procedentes de las ferrerías o la lingotería importada a base de cilindros, hornos de reverbero, puddlers y modernos trenes de laminación. Y otros finalmente, se dirigieron, dentro de la misma línea de cambio, avanzando hacia las modernas técnicas de la fundición o segunda fusión. Hasta 1848 el cambio tecnológico de la siderurgia vasca se asemejó más bien al patrón continental, aunque con matices, sin afectar fundamentalmente a la elaboración primaria, que era obra exclusiva de la siderurgia tradicional autóctona y de la moderna siderurgia extranjera.

Tabla 8: Establecimientos siderúrgicos en España y en el área vasca en 1848

\begin{tabular}{|l|c|c|c|c|c|c|}
\hline 1848 & Altos Hornos & $\begin{array}{c}\text { Reverberos } \\
\text { afinación }\end{array}$ & $\begin{array}{c}\text { Reverberos } \\
\text { moldería }\end{array}$ & $\begin{array}{c}\text { Cubilotes } \\
\text { moldería }\end{array}$ & $\begin{array}{c}\text { Hornos } \\
\text { mallaje }\end{array}$ & Ferrerías \\
\hline Álava & 2 & 1 & 1 & 1 & 3 & 1 \\
\hline Guipúzcoa & - & - & 3 & 3 & - & 52 \\
\hline Navarra & 3 & 2 & - & - & - & 23 \\
\hline Vizcaya & 1 & 3 & - & 6 & 2 & 110 \\
\hline España & 30 & 45 & 16 & 17 & 17 & 366 \\
\hline
\end{tabular}

Fuente: BILBAO BILBAO, L.M.: "La primera etapa...Op. cit., p. 227.

Tabla 9: Establecimientos siderúrgicos en el área vasca (1848-1882)

\begin{tabular}{|c|c|c|c|c|c|c|}
\hline \multirow{3}{*}{ Período } & \multicolumn{4}{|c|}{ Vizcaya } & \multicolumn{2}{|c|}{ Álava, Navarra y Guipúzcoa } \\
\hline & \multicolumn{2}{|c|}{ Procedimiento indirecto } & \multicolumn{2}{|c|}{ Procedimiento directo } & \multirow{2}{*}{$\begin{array}{l}\text { Procedimiento } \\
\text { indirecto vegetal }\end{array}$} & \multirow{2}{*}{ Ferrerías } \\
\hline & Vegetal & Coque & Modernos & Antiguos & & \\
\hline $1848-1849$ & 1 & - & - & 110 & 5 & 76 \\
\hline $1859-1860$ & 4 & 1 & 17 & 21 & 9 & 53 \\
\hline $1871-1872$ & 4 & 3 & 18 & 5 & 10 & 19 \\
\hline $1880-1882$ & 6 & 7 & 7 & - & 7 & 9 \\
\hline
\end{tabular}

Fuente: BILBAO BILBAO, L.M.: "La primera etapa...Op. cit., p. 232.

Si retomamos los datos referidos al consumo de superficie forestal en Estados Unidos, concretamente el de 1862, fecha en la que se sitúa en las 10.125 hectáreas ${ }^{63}$,

63 GORDON, R. B.: Op. cit., pp. 40-44; WILLIAMS, M.: Op. cit., p. 316. 
y suponemos la existencia de 439 altos hornos que utilizaban carbón vegetal, obtenemos un consumo de 23,06 hectáreas de bosque por alto horno; cantidad ciertamente alejada de las 2 hectáreas que consumía cada una de las 51 ferrerías guipuzcoanas entre 1845-1850. Ello nos ayuda a comprender porqué en un territorio de 199.700 hectáreas, como era Guipúzcoa, era tan difícil y poco recomendable el establecimiento, durante largos períodos de tiempo, de altos hornos que consumiesen carbón vegetal y porqué se mantuvieron sistemas arcaicos que garantizaban un aprovechamiento sostenible del bosque. De haberse establecido altos hornos con consumo de carbón vegetal en Guipúzcoa, y suponiendo que se hubiesen mantenido los 51 establecimientos que existían en 1845-1850 o los 53 hacia 1859-1860, con un consumo como el de los blast furnaces norteamericanos, el consumo anual hubiese sido de 1.176,06 hectáreas, esto es, ocho o nueve veces el consumo de las ferrerías tradicionales, lo cual era inabarcable, pues hubiese supuesto la destrucción prácticamente total del territorio arbolado guipuzcoano en menos de un cuarto de siglo. Si consideramos que el espacio arbolado ocuparía en 1845-1850 en torno a un 15\% de la superficie total de la provincia, ese consumo hubiese supuesto reservas de carbón en leña para un máximo hipotético de 25 años, lo cual era inviable.

La agonía de las ferrerías vascas se produjo tras la II Guerra Carlista (18721876): las últimas en Guipúzcoa fueron Mirandaola y Bengolea (Legazpia) y Azkue (Ibarra) en 1880-81 y en Vizcaya Aranekola (Durango) y Pobal (Galdames) en 1867. Pero hasta entonces consiguieron convivir con modelos más avanzados. En 1848 Antonio Larrea fundó una fábrica de hierro colado al carbón vegetal en Araya (Álava) ${ }^{64}$. La fundición de San Pedro de Elgóibar nació en 1877 basada en hornos de carbón vegetal y de pudelado, aunque fue renovada en 1905 con dos hornos Martín-Siemens ácidos. La fábrica de hierros de San Martín en Beasain refleja la continuidad de la tradición del hierro en la economía vasca, desde los modos tradicionales hasta la actualidad. Su historia es un testimonio del tránsito d e la ferrería a la fábrica grande. La iniciativa partió de dos ferrones, Domingo de Goitia y Martín Usabiaga, explotadores de las ferrerías de Yurre y Yarza. En 1860 se asociaron con José Francisco de Arana, vecino de Beasain dueño del término llamado "Urbieta", que acabará constituyendo el núcleo de la Compañía Auxiliar de Ferrocarriles (CAF). En 1862 Goitia, Usabiaga y Arana levantan en la fábrica de hierros de San Martín el primer alto horno moderno de la provincia, pero de carbón vegetal, con mineral de Cerain y Mutiloa. Tres años más tarde ponen un segundo horno. Tras la II Guerra Carlista, en 1878 se aplica del método Bessemer, que producirá los primeros aceros en $1885^{65}$.

64 SÁEZ GARCÍA. M. A.: Una contribución a la historia de la siderugia española: la fábrica de San Pedro de Araya (1848-1935), Vitoria, 1998.

65 Ibidem, pp. 167-168 y 201-203. 
Con todo, en el procedimiento indirecto predominaban los hornos alimentados con carbón vegetal. Ni tan siquiera con la puesta en marcha, a fines de 1880, de los cuatro hornos de San Francisco, el número total de instalaciones que fundían con combustible mineral superaba el de las alimentadas con carbón vegetal. Tales innovaciones sólo se dieron en Vizcaya, pues el resto de territorios históricos jamás se inició durante este período en la fusión al coque. La exclusiva del hierro colado obtenido al carbón vegetal resistió hasta 1850, y si bien en el decenio de los setenta se pasó hacia un cierto equilibrio, desde 1880 se quebró a favor de la hegemonía de la fusión al coque para la obtención del arrabio. Sólo en Vizcaya, porque el resto mantuvo el carbón vegetal. Hasta 1859 el predominio productivo de hierro forjado siguió recayendo sobre las ferrerías que seguían produciendo tanto como los modernos altos hornos. En Guipúzcoa y Navarra su resistencia fue fuerte a desaparecer pues en la década de los años sesenta producían todavía el 30\% del total del hierro forjado. Entre 1860 y 1880 se dio una transición de modelos productivos ${ }^{66}$.

Por tanto, durante todo el siglo XIX, la industria siderúrgica, y dentro de ella las ferrerías, siguieron siendo un factor importantísimo de destrucción de la masa forestal. Ésta, junto a las desamortizaciones, la expansión de la agricultura y la ganadería, la construcción naval, las papeleras y fábricas, la expansión del ferrocarril o la minería, explican la importante reducción de la masa forestal guipuzcoana durante el siglo XIX, que provocó la aparición de los servicios forestales a principios del siglo $\mathrm{XX}^{67}$.

Tabla 10: Terrenos forestales de Guipúzcoa exceptuados de la desamortización por razones de utilidad pública (1897)

\begin{tabular}{|c|c|}
\hline Partidos judiciales & Hectáreas \\
\hline Azpeitia & 11.308 \\
\hline San Sebastián & 5.027 \\
\hline Tolosa & 13.825 \\
\hline Vergara & 2.630 \\
\hline TOTAL & 32.790 \\
\hline
\end{tabular}

Fuente: AYERBE IRIBAR, R.M.: Servicio forestal de Gipuzkoa. Tomo I: Desde los origenes a 1925, Donostia, Diputación Foral de Gipuzkoa, 2005, pp. 525-532.

Como se puede observar a través de la tabla 12, la extensión de la superficie forestal guipuzcoana en el año 1897 representaba un 16,41\% de la superficie total de la provincia de Guipúzcoa (incluída Oñate). Guipúzcoa estaba poblada, en primer lugar, por hayas (Fagus Sylvatica) y, en segundo lugar, por robles (Quercus pedunculata), a diferencia de lo que ocurría en 1784, cuando el predominio era de los últimos, segui-

66 BILBAO BILBAO, L.M.: "La primera etapa...Op. cit., pp. 225-234.

67 ARAGÓN RUANO, A.: “Basoa Euskal Herriko historian zehar”, Uztaro, 29, 1999, pp. 25-38. 
dos a corta distancia por las primeras. El mencionado porcentaje es inferior al de la superficie arbolada de Guipúzcoa en 1784, que se situaría en un 20-25\% de la superficie total de la provincia. No obstante, para ponderar en su justa medida esos datos, es imprescindible tener en cuenta que ya para esa fecha las ferrerías habían interrumpido su actividad y tanto las instituciones provinciales como las municipales habían continuado con su labor repobladora, no sólo con especies autóctonas, sino ya con especies foráneas, todo lo cual, sin duda alguna, ayudó a maquillar la situación. Esto supone que la labor repobladora que se inició en 1749 y prosiguió a lo largo del siglo XIX tuvo sus frutos. Permitió, al menos, que la situación forestal guipuzcoana se mantuviese en unos niveles aceptables y no empeorase en exceso comparada con la que tenía a fines del siglo XVIII. Es más, las ferrerías guipuzcoanas del siglo XIX, cuyo número fue menor que las que existían durante el siglo XVIII, contaron con una extensión poblada de bosques similar a la de aquéllas, lo que, una vez más, demuestra que la cantidad de leña a disposición de cada una de las factorías siderúrgicas -también de madera para el resto de actividades- durante el siglo XIX aumentó y les permitió contar con más y más barata leña para carbón. La siderurgia, cuyo poder destructor a nivel global, como podemos apreciar en la tabla 7, irá siendo menor a medida que avanza el siglo XIX, fue una de esas actividades: las 26 hectáreas anuales que consumían las ferrerías guipuzcoanas en 1871 están a una distancia abismal de las 800 que consumían 300 años antes. Todo ello no obsta para que la situación del bosque a finales del siglo XIX fuese preocupante y obligase a las autoridades a movilizarse.

\section{Conclusiones}

Todo indica que la deforestación, que tuvo sus primeros episodios ya en los siglos XIV y XV, se agravó a partir de los siglos XVII y XVIII, y tomó tintes irreversibles a fines del siglo XVIII y comienzos del XIX ${ }^{68}$. A pesar de ello, los resultados de la política repobladora iniciada a mediados del siglo XVIII y prolongada a lo largo de toda la siguiente centuria, se dejaron sentir a partir del final de la Guerra de la Independencia, permitiendo que la masa forestal se mantuviese cerca de las cifras alcanzadas hacia 1784 .

La manifiesta preocupación de la Provincia por el retroceso del bosque fue expresada a través de la Ordenanza de plantíos de 1548. Al mismo tiempo, se consta-

68 Para el caso de Cantabria, Aedo mantiene que el Renacimiento coincidió con una aceleración del proceso de degradación del bosque, que para el siglo XVIII era evidente, y cuyo resultado fue que, a principios del siglo XIX, los bosques habían desaparecido casi por completo en el interior de la dotación de montes de las Reales Fábricas. AEDO, C.: Op. cit., pp. 44, 50, 57. 
taba la escasez de madera y de piezas para la construcción naval, principalmente en la costa, durante el siglo XVI, aunque nunca faltó la leña para las ferrerías. Dentro de este fenómeno se debe mencionar la aparición -y posterior generalización- de los trasmochos guiados o "ipinabarros", con "horca y pendón”, que evidencia la escasez de madera, el retroceso de la masa boscosa y de su productividad, y su solución momentánea. Además hay que recordar la política de repoblación gestionada por el Corregidor desde 1575, ante la preocupación de la Corona, a pesar de que en términos generales la situación no era irremediable a comienzos del siglo XVII, como lo prueba el hecho de que las repoblaciones no fuesen excesivamente altas. El empeoramiento de la situación fue ostensible, desde mediados del siglo XVII, como denota el caso de Azcoitia y el hecho de que el capítulo VIII del título 38 incluyese la necesidad de erigir viveros, destinados a la repoblación ${ }^{69}$.

A consecuencia del palpable mal estado de la masa forestal guipuzcoana, se formuló el Reglamento de Montes en 1738 y la Ordenanza de Montes de 1749, prueba de que la situación comenzaba a hacerse insostenible y de que las instituciones eran conscientes de ello. A pesar de los esfuerzos realizados desde 1749, el problema no fue solucionado; más aún, la situación en 1818 era ya irreversible, aunque durante el siglo XIX, sin duda, se agravó, entre otros factores, por la prolongada acción de la industria siderúrgica que, con modelos arcaicos o renovados, siguió consumiendo ingentes cantidades de carbón vegetal y extensiones de bosque. No obstante, a pesar del manifiesto retroceso de la masa forestal, la reducción del número de factorías siderúrgicas, junto a factores como la generalización del método del trasmochado, los resultados de la política regeneracionista desde mediados del siglo XVIII, que obtuvo sus frutos durante el siglo XIX, y el acceso a nuevas fuentes de aprovisionamiento, gracias a la riqueza forestal de ciertos territorios limítrofes, pusieron en manos de las ferrerías supervivientes un rico y barato combustible, al menos hasta mediados de siglo, que hizo viable su continuación a pesar de contar con una tecnología arcaica. Es decir, se produjo la paradoja de que, a pesar de producirse el retroceso de la masa forestal guipuzcoana, las ferrerías que sobrevivieron al cambio de siglo y al alza de los precios, hasta el primer lustro del siglo XIX, contaron para cada una de ellas con mayores cantidades de leña y a precios más moderados.

Cuatro siglos de lucha, principalmente de las autoridades, en pos de la sostenibilidad de la explotación forestal y las actividades productivas, quedaban atrás, sin conseguir solucionar el problema de la deforestación. La solución comenzó a vislumbrarse con la aparición de los Servicios forestales, a comienzos del siglo XX, y con la introducción de especies arbóreas foráneas de rápido crecimiento, como el

69 ARAGÓN RUANO, A.: El bosque guipuzcoano...Op. cit., pp. 40-43 y 97-101. 
pino insignis, el eucalipto, el alerce, etc., que en la actualidad nos dan un panorama de recuperación de la masa forestal, tanto de especies autóctonas como alóctonas. Ya para entonces las ferrerías había exhalado su último suspiro y las nuevos altos hornos y factorías siderúrgicas se surtían de carbón mineral. En el censo de 1996 Guipúzcoa contaba con tres veces más superficie boscosa que en 1784, concretamente 118.225 hectáreas de arbolado $^{70}$, esto es, el $60 \%$ de la superficie total de la provincia, frente al $20-25 \%$ de 1784 o al $16 \%$ de 1897 , lo cual augura un futuro alentador. Sin duda el abandono, a lo largo de la segunda mitad del siglo XX, de ciertas prácticas industriales y agrícola-ganaderas, predominantes en épocas pasadas, han favorecido esta recuperación y la reorientación de las masas forestales hacia aprovechamientos relacionados con el ocio y el esparcimiento. 